\title{
Las originales perdidas: una tradición literaria de mujeres para integrar el canon nacional
}

\author{
María Rosa Lojo • \\ Escribir más o menos bien, más o menos mal, pero como una mujer [...] \\ Pues entiendo que una mujer no puede aliviarse de sus sentimientos \\ y pensamientos en un estilo masculino, del mismo modo \\ que no puede hablar con voz de hombre.
}

(Oсамро, 1981: 9-10)

Esta frase de Victoria Ocampo, estampada en la Carta a Virginia Woolf que antecede la Primera Serie de sus Testimonios (1 ${ }^{\text {a }}$ ed 1935), se convirtió en cita tópica. Claro que, desde la mirada actual, tal enunciación aparentemente simple se complejiza y se problematiza. ¿Qué entendemos hoy por ser hombre, por ser mujer? No podemos postular solo dos géneros, mujer y varón, sino múltiples y matizadas identidades que buscan y encuentran otros lugares. Ya no cabe ceñirse a la idea de género determinado por una biología binaria. La multiplicidad de las diferencias que desbordan lo biológico exhibe su condición de constructo social. No solo porque hay «cuerpos desobedientes» (Fernández, 2004) — travestis, trans_ que se niegan a adscribirse al género asignado desde la biología, sino porque esos cuerpos tampoco se limitan a «pasarse al género contrario", con todos los estereotipos y regulaciones que lo definen; antes bien, se plantean conductas y valores que exceden la bipolaridad. El género y el cuerpo mismo, según la filósofa Judith Butler, son estructuras imaginarias e imaginadas. Su artificialidad es puesta de manifiesto, justamente, por las prácticas consideradas transgresoras. En una comunidad dada, el cuerpo, su apariencia, su ropa, sus conductas, se conforma como un espejo y un efecto de los condicionamientos de género y no a la inversa (Vartavedian, 2007).

- Hija de españoles, escritora e investigadora. Es Doctora en Letras por la UBA e Investigadora principal del CONICET. Profesora titular y Directora del Centro de Estudios Críticos de Literatura Argentina de la Universidad del Salvador (Bs. As). Su obra creativa incluye libros de microficciones líricas/poemas en prosa, cuatro colecciones de cuentos y nueve novelas, la más reciente es Solo queda saltar, de 2018. Su obra fue traducida a más de seis idioma y recibió numerosos premios y reconocimientos, entre los cuales el Gran Premio de Honor de la Sociedad Argentina de Escritores en 2018. 
Cuando Victoria Ocampo escribía su carta a Virginia Woolf, esta problemática no era por cierto tan evidente. Pero sí resultaba muy claro para ambas que esos seres humanos catalogados como mujeres estaban en franca desventaja con respecto a los varones, en cuanto a sus derechos, sus oportunidades, su participación en la actividad pública, política, profesional y cultural. Y, por supuesto, en cuanto al interés y el reconocimiento que las tareas masculinas (por ende, universales) y femeninas (particulares) alcanzaban en la tabla de valores de la sociedad.

Tanto en esta carta a Virginia Woolf, como en el ensayo La mujer y su expresión (1936), Victoria Ocampo propone dos tesis atendibles: 1. Que la historia de la literatura universal ha sido, mayormente, un largo monólogo masculino, porque la literatura escrita por mujeres ocupa un lugar minoritario (tanto en publicación como en prestigio). 2. Que los varones, representantes del hombre universal, no parecen haber mostrado, tampoco, mayor inquietud por escuchar lo oculto tras ese silencio femenino. Por el contrario, han contado más bien con no ser interrumpidos en su secular monólogo. En todo caso, se han apropiado de la palabra y de la imagen de las mujeres. Las han representado, han hablado en su nombre, las han construido a su manera como sus personajes y creaciones. Hablar en nombre propio; hablar, también, desde la experiencia de sujeción que ha definido el lugar femenino en la Historia: esa es, para Ocampo, la asignatura pendiente de la que las mujeres escritoras podrán y deberán hacerse cargo.

Cabe preguntarnos, claro, cómo nos hacemos cargo. Las mujeres no somos un mero colectivo. Somos singularidades. Si nacer con un cuerpo biológicamente clasificable como masculino o femenino, no nos confiere de manera automática identidades sexo-genéricas, tampoco pensamos ni escribimos en bloque solo porque aceptemos reconocernos como mujeres. Ni siquiera si compartimos clase social, etnia y orientación sexual.

Sin embargo, se habla a menudo de literatura femenina, en mal y en buen sentido. Con intención denigratoria, que alude a estereotipos y clichés representativos, sentimentales o triviales, asociados a las mujeres (aunque no solo practicados por ellas). Y con propósitos reivindicatorios. Críticas feministas, como Michèle Soriano, han visto una "anamorfosis performativa» (2010), una distorsión o intervención que las creadoras imprimen sobre el canon y los géneros literarios consagrados por una cultura predominantemente patriarcal. Tal capacidad de alteración distinguiría y validaría a las autoras originales frente a otras convencionales, dispuestas a seguir carriles previstos. Pero más allá del género sexual, ciertamente toda obra creativa, ya sea escrita por varones o por mujeres, modifica y enriquece en algún sentido y a su modo un canon y unas formas genéricas y generales sobre las que se moldearon, de todas maneras, grandes textos literarios, aun bajo el régimen patriarcal.

No podría definir un ejercicio literario femenino o propio de las mujeres, considerándolas como un todo más o menos homogéneo, así como no lo haría en el caso de los varones. También me parece discutible apelar a pautas formales específicas que por sí mismas legitimen una literatura femenina frente a preceptivas o normativas de origen patriarcal.

Pero puedo referirme a mis propias prácticas de lectora y escritora, que se insertan en un extenso horizonte histórico donde la producción literaria de mujeres ha sido, y aun es, postergada e invisibilizada. Como lectora-alumna, desde la escuela a la universidad, mi primera impresión ante esa literatura de mujeres fue la de vacío. Fuera de algún soneto de Sor Juana, no recuerdo haber leído en el secundario 
ninguna obra escrita por una congénere. El ingreso a la Carrera de Letras, en la UBA, no mejoró las cosas. Así consta en Todos éramos hijos (2014), una novela autoficcional, que se ubica en el primer lustro de la década del 70 :

Nunca estudiaría Frik en el canon que incluían las asignaturas de su carrera, un texto de firma femenina. Quizá solo el azar había hecho que no se explicasen en los programas las obras de las pocas autoras reconocidas, como Sor Juana Inés de la Cruz, Santa Teresa, Jane Austen o Virginia Woolf. Pero todas sus lecturas de escritoras, que habían empezado en la pequeña biblioteca de Ana, su madre, continuarían al margen de los claustros, a veces entre las paredes heridas y descascaradas de los Institutos de Investigación, en la calle 25 de mayo, donde encontraría tesoros ocultos que ningún profesor le había recomendado aún.

Cada vez fui desconfiando más de ese «azar» que siempre, en todo caso, tenía un mismo efecto: la inexistencia (o la eventual inclusión, solo a título excepcional) de nombres de autoras en los curricula escolares y académicos. Si bien las mujeres eran la minoría literaria, habían escrito y publicado libros. ¿Por qué no se los consideraba? ¿Estaban «mal escritos»? ¿Muy por debajo de los estándares estéticos universales (léase, masculinos)? ¿Cuál era, en todo caso, el criterio de la «buena escritura»? ¿Tal vez narraban experiencias juzgadas como deleznables, insignificantes, menores y minorizadas, porque eran las experiencias del género subalterno?

De ese azar, o causalidad, no se escapa ni siquiera una abanderada del género, Victoria Ocampo, musa rebelde. Precisamente en su carta a Virginia Woolf, habla de su pobreza de escritora latinoamericana, sin antepasadas literarias, contrastada con la riqueza de la tradición femenina británica en la que se apoya Virginia. Sin embargo, ignora por completo la obra de una compatriota aún muy cercana en el tiempo: Eduarda Mansilla (1834-1892), perteneciente, como ella, al patriciado, narradora y compositora musical pionera, políglota, autora de una gran novela originalmente escrita en francés: Pablo, ou la vie dans les Pampas (1869). Seguramente Ocampo conoció en su infancia los cuentos de la Condesa de Ségur, pero no menciona los de Eduarda, primeros escritos y publicados, en 1880, por una autora argentina para niños argentinos. ¿Figuraría la Mansilla en su biblioteca familiar? Es difícil. En el entresiglos de la "sensibilidad victoriana», como la llama Pedro Barrán, se prefería ocultar a las damas que hubiesen incurrido en el delito de la exhibición intelectual. Por lo demás, aun conociéndola, quizá Victoria (abrumada por complejos geopolíticos) hubiera buscado distanciarse de esta señora criolla y cosmopolita que olía a pasado rioplatense, como los muebles de los cuadros de Figari, pero a quien, en varios aspectos, ella misma se parecía mucho.

Entablar un diálogo, desde la ficción, y también desde la investigación y la crítica, con mujeres como Eduarda y como Victoria, sujetos activos de una Historia cultural que enriquecieron y modificaron: esa ha sido, para mí, una de las maneras que elegí para hacerme cargo del largo silencio femenino. Además de fundar una colección de ediciones críticas donde se volvieron a publicar buena parte de los libros de Eduarda, le dediqué una novela a cada una: Una mujer de fin de siglo (1999), sobre Eduarda y Las libres del Sur (2004), que gira en torno a Victoria. Ambas ficciones conjeturan a qué se enfrentaron esas creadoras, dentro y fuera de sí mismas, con qué contradicciones debieron lidiar, qué legado dejaron, quiénes eran, quiénes hubieran querido ser; también, inevitablemente, se preguntan en qué sentido descendemos de ellas, por qué son nuestras precursoras. Tuvieron 
entre sí muchas diferencias, de las que me he ocupado en varios textos críticos. Pero quiero destacar cierto enfoque compartido de la literatura. Las dos prestaron en sus textos consideración particular a una femineidad que percibían como injustamente inferiorizada: en el reverso oculto de la épica varonil, en la locura que se escapa por los bordes de la sumisión doméstica (Eduarda); en la belleza que se niega a constituirse como mero ideal erótico inspirador para la inteligencia activa masculina (Victoria). Ninguna de ellas escribió ni quiso escribir solo para sus congéneres. Creyeron, con todo derecho, que su literatura podía ser reveladora para ambos géneros. Y, como lo reclamaba Victoria Ocampo, no solo pusieron de manifiesto la subjetividad femenina, sino que discurrieron sobre ese otro, «el hombre, a su vez, en calidad de testigo sospechoso» $(1936,23)$.

Pienso por fin especialmente en Eduarda, que, cuando la literatura nacional era aún un proyecto naciente y en marcha, pugnó diez años, como lo recuerda Sarmiento, «por abrirse las puertas cerradas a la mujer, por entrar como cualquier cronista o reporter en el cielo reservado a los escogidos (machos), hasta que al fin ha obtenido un boleto de entrada a su riesgo y peligro" (El Nacional, 1885). Y logró publicar, también, libros que apelaban a todas y todos, desde lo personal y lo político, aportando a la construcción simultánea de un país y de su literatura.

Falta aún que el tan mentado «sistema literario argentino» en cuyos lugares centrales siguen entronizados «los escogidos (machos)», reconozca en un pie de igualdad a estas «originales perdidas» (originales por únicas y también por fundadoras) y a quienes las sucedieron. 


\section{Nota}

${ }^{1}$ La carta fue publicada por primera vez en la Revista de Occidente, $\mathrm{n}^{\circ}$ 137 (1934).

\section{Referencias bibliográficas}

Fernández, J. (2004). Cuerpos desobedientes. Travestismo e identidad de género. Buenos Aires: Edhasa.

Lojo, M.R. (2010). «Sarmiento crítico literario y promotor de mujeres escritoras» en de Marco, M. y González, J. (eds.) Visiones de Sarmiento. Buenos Aires: Facultad de Filosofía y Letras, Universidad Católica Argentina, pp. 121-131.

(2014). Todos éramos hijos. Buenos Aires: Sudamericana, 2014.

Ocampo, V. (1981). «Carta a Virginia Woolf» en Testimonios. Primera Serie 1920-1934. Buenos Aires: Sur, pp. 7-14.

(1936). La mujer y su expresión. Buenos Aires: Sur.

Soriano, M. (2010). «Políticas transgénero y política de la in-diferenciación: Doquier de Angélica Gorodischer» en Lojo, M.R. y Soriano, M. (dirs.) Identidad y narración en carne viva. Cuerpo, género y espacio en la novela argentina (1980-2010). Buenos Aires: Ediciones Universidad del Salvador. Convenio entre Universidad del Salvador y Universidad de Toulouse II - Le Mirail, pp. 351-376.

VARTABEDian, J. (2007). «El cuerpo como espejo de las construcciones de género. Una aproximación a la transexualidad femenina». Quaderns-e de l'Institut Català d'Antropologia, (10/b). [en línea] Consultado 12-11-2018 en http://www.raco.cat/index.php/QuadernseICA/article/ view/109038/0

\section{Lojo, María Rosa}

«Las originales perdidas: una tradición literaria de mujeres para integrar el canon nacional». El hilo de la fábula. Revista anual del Centro de Estudios Comparados (19), 175-179. 